\title{
Impact functions for land-use-induced surface warming, and their applications in uncertainty analysis
}

\author{
Ryuhei Yoshida ${ }^{1,2}$, Toshichika Iizumi ${ }^{1}$, Motoki Nishimori ${ }^{1, *}$ \\ ${ }^{1}$ Agro-Meteorology Division, National Institute for Agro-Environmental Sciences 3-1-3, Kannondai, Tsukuba, Ibaraki, Japan \\ ${ }^{2}$ Present address: Graduate School of Science, Tohoku University, Sendai, Japan
}

\begin{abstract}
We developed statistical models (called impact functions) in this study that mimicked the responses of summer mean, maximum, and minimum surface temperatures to given land-use changes (LUC) simulated with a regional climate model (RCM). The island of Shikoku in western Japan was used as an example. The impact functions were based on the RCM-simulated sensitivity of temperatures to changes for each of 5 land-surface parameters (surface albedo, evaporative efficiency, roughness length, heat capacity, and thermal conductivity). Thus, the relative importance of a specific land-surface parameter for the local temperature (e.g. greater sensitivity of daily mean temperature to evaporative efficiency) determines the impact functions. We compared the impact functions to the independently evaluated RCM simulations to assess how well our results matched the historical LUC-induced RCM warming simulations in this area between 1987 and 2006. The impact function performance varied with grid size: the $10 \mathrm{~km}$ results matched the RCM simulations best, with an error of 10-15\%. Next, the impact functions were used to estimate the potential warming range for different LUC scenarios. Given the geographical distribution of present-day land use/land cover, the Monte Carlo simulations with impact functions indicate that LUC-induced changes in summer mean temperature potentially range from -0.4 (when forest is converted to paddy) to $+1.3{ }^{\circ} \mathrm{C}$ (when forest is converted to building lots). This result indicates that, on an area mean basis, the cooling achieved through land-use management is limited in its ability to offset climate change-induced warming in future decades.
\end{abstract}

KEY WORDS: Impact function $\cdot$ Land-use change $\cdot$ Surface warming $\cdot$ Shikoku $\cdot$ Regional climate model $\cdot$ Uncertainty analysis

\section{INTRODUCTION}

Land-use changes (LUCs) affect surface temperature by modifying vegetation-soil-atmosphere exchanges of water and energy (Kalnay \& Cai 2003). The impacts of historical LUCs (such as deforestation, urbanization, and increasing or decreasing cropland) on surface temperature changes have been extensively evaluated (e.g. Hahmann \& Dickinson 1997, Fu 2003, Sen et al. 2004, Yoshida et al. 2012).

At a regional scale, a method frequently used for the assessment of LUC-induced surface temperature changes is the use of a regional climate model (RCM) with various land-surface boundaries (e.g. Yoshida et al. 2012). Although RCMs can be used for physicsbased assessments, their high computational costs hinder the application of RCMs to uncertainty analysis (e.g. Mariotti et al. 2011) when computer resources are limited. Uncertainty analyses requires many climate downscaling simulations with various LUC scenarios and multiple climate projections, which are derived from different global climate models (GCMs) and different greenhouse gas and aerosol emission scenarios.

When computer resources are limited, the impactfunction method (also known as statistical emulation) 
can be used as an alternative to uncertainty analysis with a computation-heavy model. The impact-function method develops a statistical model that mimics the response of a complex model to a given forcing change (Murphy et al. 2007, Hanasaki et al. 2007, Iizumi et al. 2009, Good et al. 2012, Ramankutty et al. 2013). When using the impact-function method, a selected number of sensitivity analyses are conducted with a complex model. In addition, a database of the model's responses to forcing changes is created. Next, a statistical model is fit to the simulated data. Iizumi et al. (2009) used this method to simulate changes in paddy rice yield in Japan for different climate change scenarios. According to Iizumi et al. (2009), the impact functions for paddy rice in Japan can accurately approximate a computationally heavy crop model for different temperatures, solar radiation values, planting dates, and $\mathrm{CO}_{2}$ concentrations. This approach allows for integrated assessment without embedding the complex crop model into an integrated assessment model. This concept has been applied to estimate the climate change impacts on crop yields (e.g. Sheehy et al. 2006, Schlenker \& Lobell 2010, Ruane et al. 2013).

The objectives of this study include the following: (1) to create impact functions for the summer mean, maximum, and minimum surface temperatures ( $T_{\text {ave }}$ $T_{\max }$ and $T_{\min }$ ) in response to a given LUC by applying the impact-function method to a $\mathrm{RCM}_{i}(2)$ to validate the developed impact functions by comparing them with RCM simulations (referred to as the RCM method); and (3) to estimate the range of possible regional surface temperature changes in different LUC scenarios using the developed impact functions. The objective variables in the impact functions included changes in $T_{\text {aver }} T_{\max }$, and $T_{\min }$ at specified spatial and temporal scales. In addition, the explanatory variables included changes in landuse/land-cover (LULC; represented by the following land-surface parameters: surface albedo, evaporative efficiency, roughness length, heat capacity and thermal conductivity). A nonhydrostatic regional atmospheric model (Japan Meteorological Agency nonhydrostatic model, JMA-NHM; Saito et al. 2007) was used as an example of a RCM. The island of Shikoku, which is located in western Japan (Fig. 1), was studied because the historical LUC-induced surface warming in this area was recently evaluated using the RCM method (Yoshida et al. 2012). In addition, paddy fields in the Shikoku area have been decreasing more rapidly $(20.3 \%$ in 2006 relative to 1987 ; MAFF 2007) than in other parts of Japan (16.1\% based on the national average), which makes this

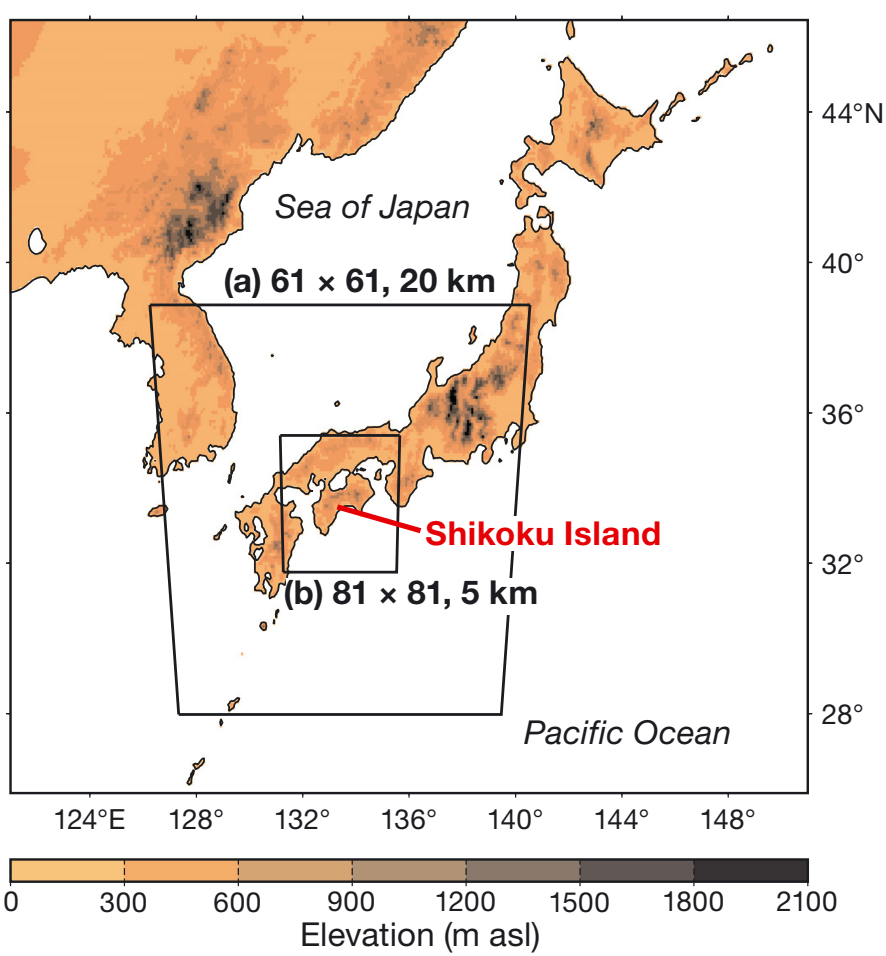

Fig. 1. Location of Shikoku and the calculation domain used in the Japan Meteorological Agency nonhydrostatic model (JMA-NHM) simulations. (a) The outer domain was $61 \times$ 61 cells with a cell spacing of $20 \mathrm{~km}$; (b) the inner domain was $81 \times 81$ cells with a cell spacing of $5 \mathrm{~km}$

area suitable for study. Fig. 2 shows the geographical distributions of LULC across the island of Shikoku.

\section{DATA AND METHODS}

The procedures that are involved in the different methods are illustrated in Fig. 3.

The derived impact functions were evaluated with the RCM method to determine their ability to simulate LUC-induced summer temperature changes across Shikoku between 1987 and 2006. Next, an uncertainty analysis was conducted to estimate the spread of the possible temperature changes in the area during the LUC scenarios. The uncertainty analysis method is described at the end of this section.

\subsection{RCM method}

Using the RCM method (Fig. 3a), 2 types of climate downscaling simulations were performed with the $5 \mathrm{~km}$ mesh JMA-NHM model for the entire Shikoku 
(a) Paddy field

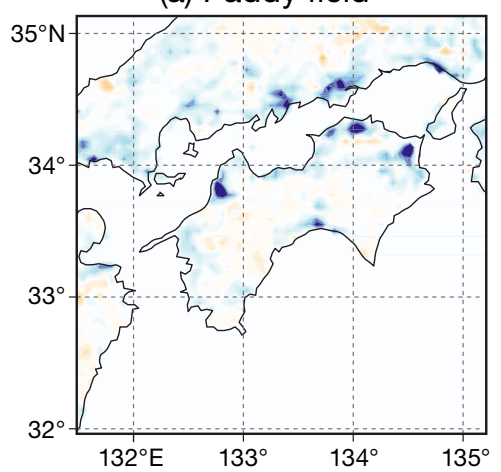

(b) Forest

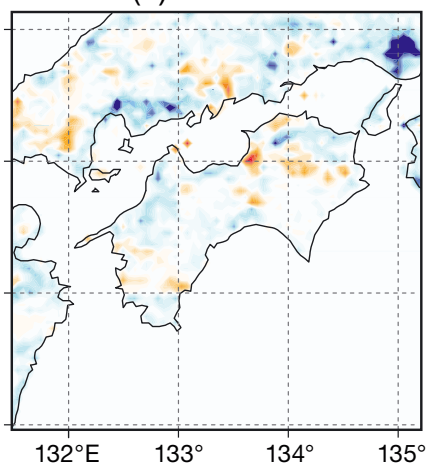

(c) Building lots

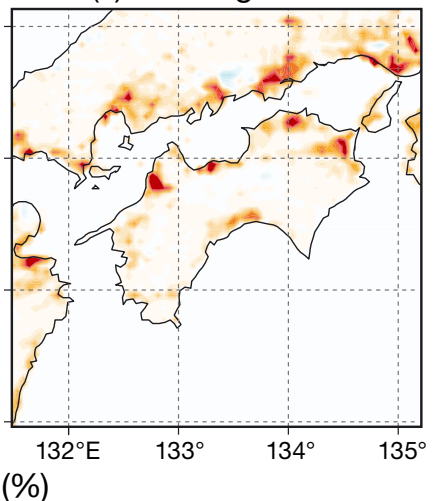

(d) Arterial roads

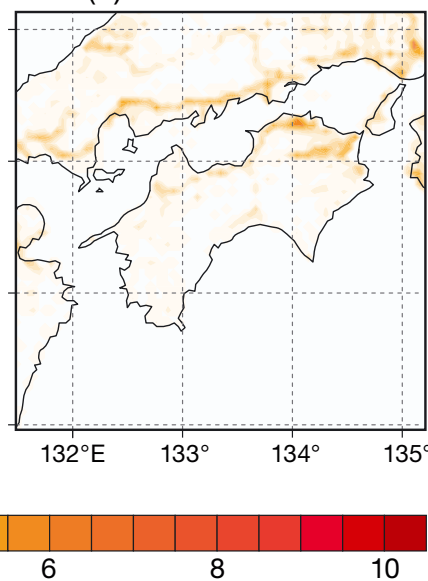

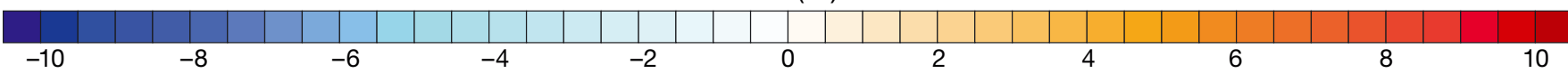

Fig. 2. Geographical distribution of the land-use change (LUC) between 1987 and 2006 (positive values represent an increase in 2006). Color scale: ratio of National Land Numerical Information grid cells (100 m mesh) that were included in the Japan Meteorological Agency nonhydrostatic model (JMA-NHM) $5 \mathrm{~km}$ mesh (\%)

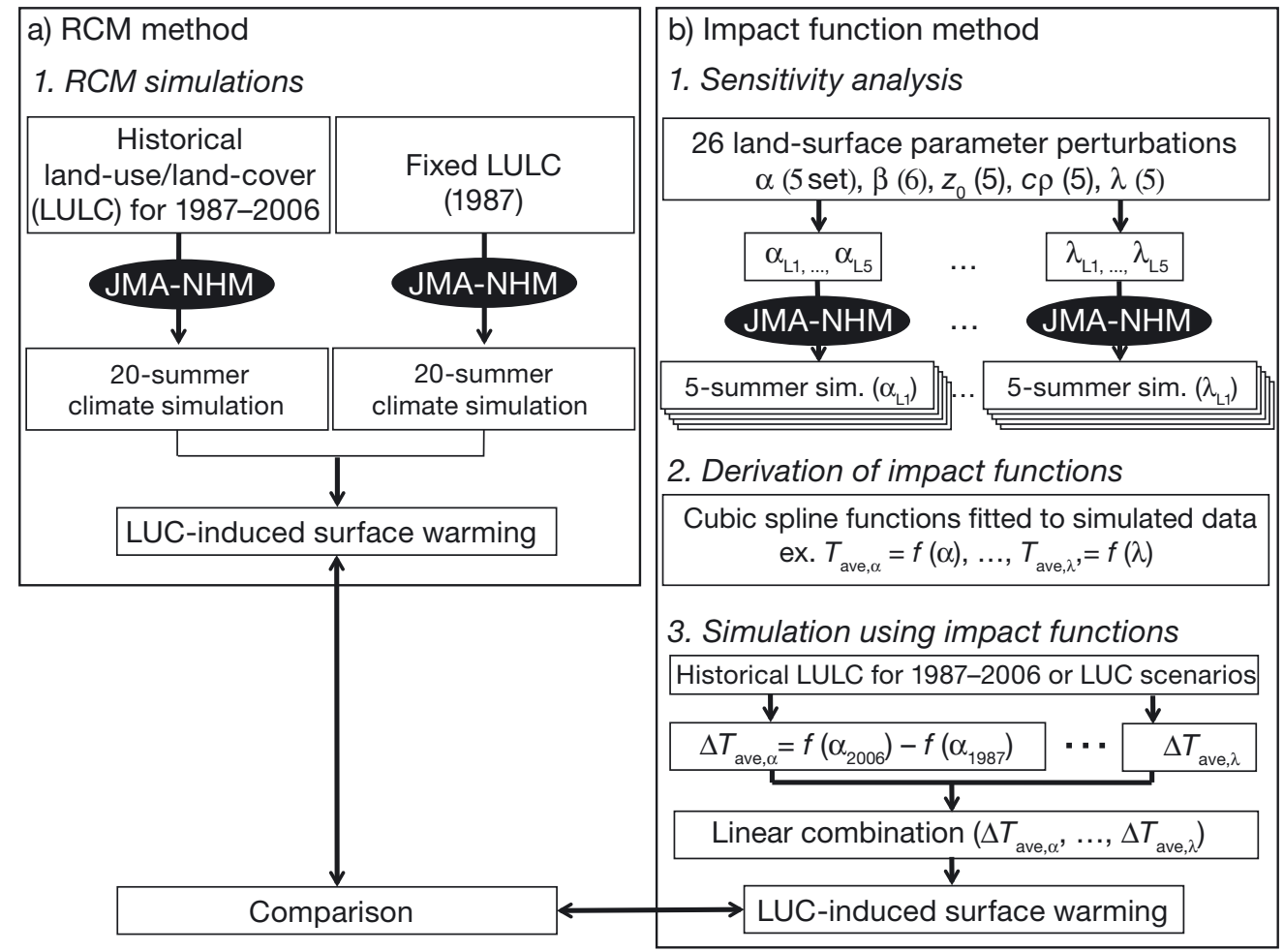

Fig. 3. Key procedure schematic for the (a) regional climate model (RCM) and (b) impact-function methods. $\alpha$ : surface albedo; $\beta$ : evaporative efficiency; $z_{0}$ : roughness length; $c \rho$ : heat capacity; $\lambda$ : thermal conductivity; $T_{\text {ave: }}$ daily mean temperature

area for $72 \mathrm{~d}$ (from 5 June to 15 August) of each year, between 1987 and 2006 (Table 1). The analysis period was the same as in a previous study (Yoshida et al. 2012), which estimated the impacts of historical LUCs on surface warming in the Shikoku area. One type of climate downscaling simulation used the historical LUCs from the National Land Numerical
Information data (NLNI; MLITT 2012). The other type of simulation used a constant LULC condition identical to the conditions in 1987 . The initial and lateral boundary conditions of the 2 simulations were based on the Japanese 25 yr Reanalysis (JRA-25; Onogi et al. 2007) and National Oceanic and Atmospheric Administration (NOAA) Optimum Interpola- 
Table 1. Common experiment design. JMA-NHM = Japan Meteorological Agency nonhydrostatic model; NOAA = National Oceanic and Atmospheric Administration; SST: sea-surface temperature

\begin{tabular}{|lll|}
\hline & Outer domain & Inner domain \\
\hline Model & JMA-NHM (Saito et al. 2007) & Same as outer domain \\
Center & $33^{\circ} 36^{\prime} \mathrm{N}, 133^{\circ} 24^{\prime} \mathrm{E}$ & Same as outer domain \\
Domain & $1220 \times 1220 \mathrm{~km}$ & $405 \times 405 \mathrm{~km}$ \\
Grid size & $20 \mathrm{~km}$ with 61 grid cells & $5 \mathrm{~km}$ with $81 \mathrm{grid}$ cells \\
Time step & $60 \mathrm{~s}$ & $15 \mathrm{~s}$ \\
Initial and boundary conditions & JRA-25 (Onogi et al. 2007) & Results of $20 \mathrm{~km}$ calculation \\
Vertical layer & 38 layers stretching over a grid of $40-1120 \mathrm{~m}$ & Same as outer domain \\
Sea surface temperature (SST) & NOAA Optimum Interpolation SST & Same as outer domain \\
Moist process & Kain-Fritsch scheme (Kain 2004) and cloud & Same as outer domain \\
Turbulent process & microphysical processes & Same as outer domain \\
\end{tabular}

tion Sea Surface Temperature data (Reynolds et al. 2002). Additional details regarding climate downscaling simulations are available in Yoshida et al. (2013).

\subsection{Impact-function method}

The impact-function method consists of the following 3 steps (Fig. 3b): (1) sensitivity analysis of the JMA-NHM model for various LULC conditions, (2) derivation of the impact functions, and (3) simulation of the LUC-induced surface temperature change with the derived impact functions.

\subsubsection{Sensitivity analysis of the JMA-NHM model}

In the JMA-NHM model, the LULC condition for a given grid cell was specified by a set of 5 landsurface parameters, including surface albedo, evaporative efficiency, roughness length, heat capacity, and thermal conductivity. The LULC data from the Global Land Cover Characterization data (with a $1 \mathrm{~km}$ grid size) (GLCC; Loveland et al. 2000) were averaged based on the allocation of the LULC data point within a $5 \mathrm{~km}$ grid cell to obtain a single set of land-surface parameter values. Although a different LULC data source was used for the impact-function method (GLCC) relative to the RCM method (NLNI), the difference in value of the present-day LULC between the 2 LULC datasets are not important for this study, because a range of land surface parameter values perturbed in the sensitivity analysis is far larger than the difference between the 2 LULC datasets.

The sensitivity analysis of the JMA-NHM model was conducted by independently perturbing the land-surface parameter values for the Shikoku area (Fig. 3b). The range and interval of each parameter value are shown in Table 2. Each parameter range was determined for all possible LULC conditions (e.g. forest, paddy field, bare soil) in the study area based on Kondo (1994). When the value of an intended parameter was modified, the values of the remaining parameters were set to their default values, which were obtained from Kondo (1994) and were based on the spatial LULC distribution of the GLCC data. Five levels were used for all parameters, other than evaporative efficiency. Six levels were used for the evaporative efficiency because the preliminary results suggested that the summer temperatures in the study area were more sensitive to this parameter than to the others. All land-surface parameters, except for those in Shikoku area, were maintained at their default values during the sensitivity analysis.

Table 2. Values of the 5 land-surface parameters ( $\alpha$ : surface albedo; $\beta$ : evaporative efficiency; $z_{0}$ : roughness length; $c \rho$ : heat capacity; and $\lambda$ : thermal conductivity) that were used for the Japan Meteorological Agency nonhydrostatic model (JMA-NHM) model sensitivity analysis. Note: the set of parameter values $\left(\alpha, \beta, z_{0}, c \rho, \lambda\right)$ that were used for some of the major land-use/land-covers are as follows: forest $=(0.1,0.3$, $0.95,1.0 \times 10^{6}$, and 0.7$)$, paddy $=\left(0.1,0.8,0.03,2.3 \times 10^{6}\right.$, and $1.6)$, and building lots $=\left(0.13,0.05,1.0,3.0 \times 10^{6}\right.$, and 2.1$)$

\begin{tabular}{|lcccccc|}
\hline \multirow{2}{*}{ Parameter } & \multicolumn{9}{c|}{ Parameter value at each level } \\
& L1 & L2 & L3 & L4 & L5 & L6 \\
\hline$\alpha$ (Dimensionless) & 0.0 & 0.2 & 0.4 & 0.6 & 0.8 & \\
$\beta$ (Dimensionless) & 0.0 & 0.1 & 0.2 & 0.4 & 0.6 & \multirow{2}{*}{1.0} \\
$\mathrm{z}_{0}(\mathrm{~m})$ & $10^{-4}$ & $10^{-3}$ & $10^{-2}$ & $10^{-1}$ & $10^{0}$ & \\
$\mathrm{c} \rho\left(10^{6} \mathrm{~J} \mathrm{~m}^{-3} \mathrm{~K}^{-1}\right)$ & 0.2 & 1.2 & 2.2 & 3.2 & 4.2 & \\
$\lambda\left(\mathrm{W} \mathrm{m}^{-1} \mathrm{~K}^{-1}\right)$ & 0.1 & 0.6 & 1.1 & 1.6 & 2.0 & \\
\hline
\end{tabular}


For each set of land-surface parameter values, a 1-summer simulation was performed for 5 different years with the JMA-NHM model (1985, 1990, 1995, 2000, and 2005). A calculation period of $72 \mathrm{~d}$ (from 5 June to 15 August) was used for each year. This simulation was performed 26 times with different parameter sets $(5$ levels $\times 4$ parameters +6 levels $\times$ 1 parameter). Although the simulation period was exactly $72 \mathrm{~d} \mathrm{yr}^{-1}$, the total number of calculations corresponded to a $9750 \mathrm{~d}$ (approximately $27 \mathrm{yr}$ ) simulation. Due to the heavy computational burden, we did not conduct a 20-summer sensitivity analysis simulation for each parameter set. In addition, we were unable to account for any cross-parameter effects. For each simulation, the results from the first $10 \mathrm{~d}$ (considered as the spin-up period) were discarded. The simulated $T_{\text {ave, }} T_{\max }$ and $T_{\min }$ values were averaged over the summer season (from 15 June to 15 August) and over 5 yr periods for each $5 \mathrm{~km}$ grid cell. These averages were used to determine the impact functions. Other parts of the JMA-NHM model, including the initial and lateral boundary conditions, were the same as the values used in the RCM method.

\subsubsection{Derivation of the impact functions}

For each grid cell, parameter, and variable $\left(T_{\text {ave, }}\right.$ $T_{\max }$ and $T_{\min }$ ), a cubic spline function was fitted to 5 (or 6) samples of the simulated 5-summer mean temperatures (Fig. 4). Because of its flexibility, we selected a cubic spline function to mimic the gradual increase or decrease in value of the temperature variables associated with the change in value of land surface parameter as shown in Fig. 4 (however, note that other nonparametric functions could be alternatives). The resulting spline functions should represent the typical responses of $T_{\mathrm{ave}} T_{\max }$ and $T_{\min }$ in each grid cell to changes in a given land-surface parameter value. By applying these functions, we derived the surface air temperature responses to land-surface parameter changes as follows:

$$
\Delta T_{\mathrm{a}}=\sum_{i=1}^{5} \frac{\delta T_{\mathrm{a}}}{\delta p_{\mathrm{i}}} \Delta p_{\mathrm{i}}
$$

where $\Delta T_{\mathrm{a}}$ is the surface air temperature change $\left(T_{\mathrm{a}}\right.$ : $T_{\text {aver }} T_{\max }$ and $T_{\min }$ ) that results from a land-surface parameter change $\left(\Delta p_{\mathrm{i}}\right)$, and $p_{\mathrm{i}}$ is the land-surface parameter (1: surface albedo, 2: evaporative effi-
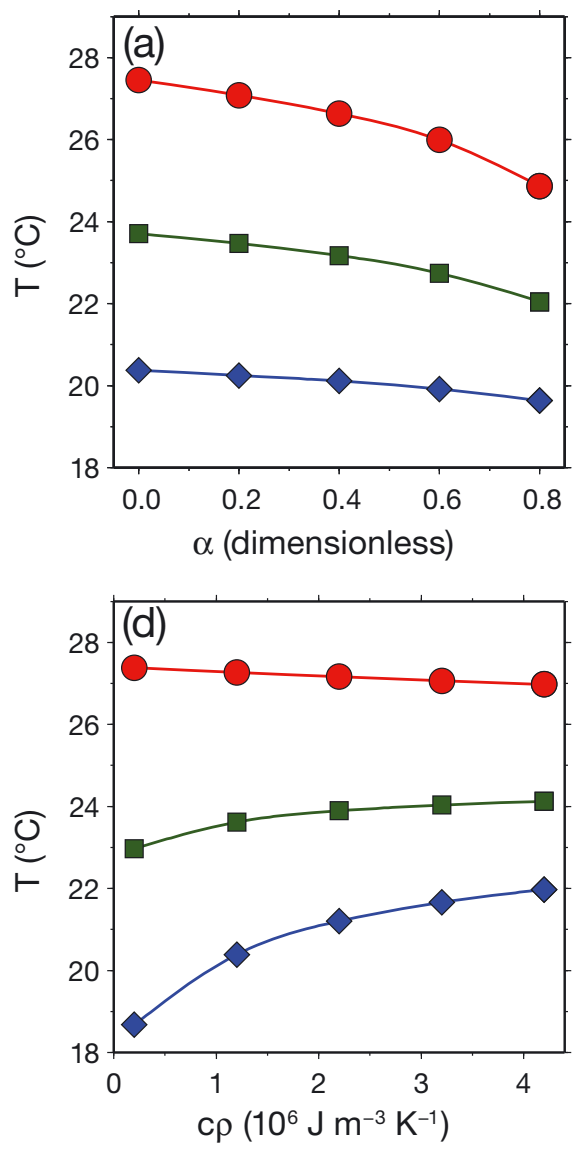
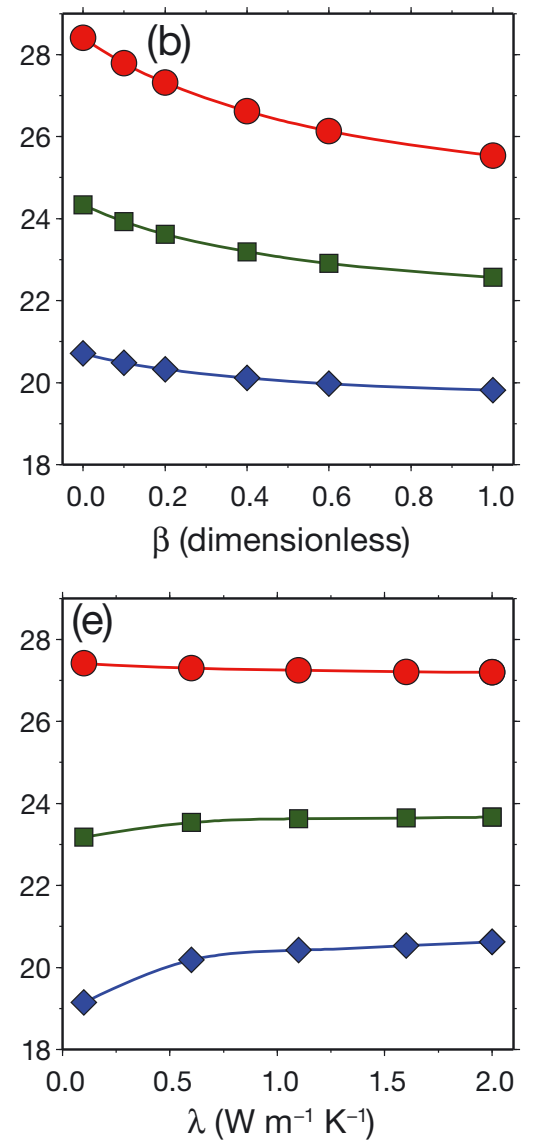

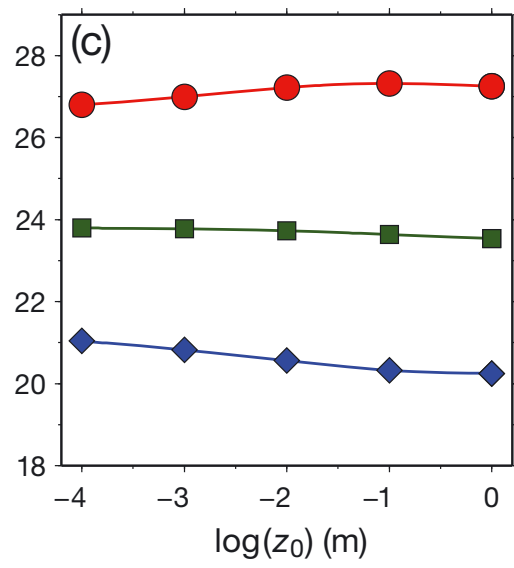

$T_{\max } \square T_{\text {ave }} \diamond T_{\min }$

Fig. 4. Five-year mean summer temperatures in Shikoku ( $T_{\text {aver }}, T_{\max }$, and $T_{\min }$ ) for various values of the landsurface parameter values: (a) surface albedo $\alpha$, (b) evaporative efficiency $\beta$, (c) roughness length $z_{0}$, (d) heat capacity $\mathrm{c} \rho$, and (e) thermal conductivity $\lambda$ 
ciency, 3: roughness length, 4: heat capacity, or 5: thermal conductivity). The partial differential coefficient $\left(\delta T_{\mathrm{a}} / \delta p_{\mathrm{i}}\right)$ was derived from the cubic spline functions.

The reliability of the RCM outputs increases with the increasing average temporal and spatial domains, which suggests that a particular spatial scale potentially provides the most accurate impact functions. To determine this scale, we examined various spatial scales as a function of the number of $5 \mathrm{~km}$ grid cells (e.g. 5, 10, 20, and $40 \mathrm{~km}$ ). In this calculation, impact functions for $T_{\text {ave }}, T_{\max }$, and $T_{\min }$ were created similarly as described above after box-averaging. For example, for the $10 \mathrm{~km}$ grid, each grid cell is composed of four $5 \mathrm{~km}$ grid point values (GPVs) that were averaged to obtain a single value for the $10 \mathrm{~km}$ grid cell. The GPVs for the other scales were computed in a similar manner.

\subsection{Validation of the impact-function method}

For the validation purpose, the composed impact functions were compared with the LUC-induced surface warming for the period 1987-2006 simulated by the RCM (Fig. 3). In the RCM method, historical and fixed LUC scenarios were converted to land surface parameters and inputted separately to the JMANHM model. Surface warming was estimated by taking their differences. In the impact function method, land surface parameters were first converted to the difference between historical and fixed LUC scenarios (i.e. $\Delta p_{\mathrm{i}}$ ) and then were applied to Eq. (1). The validation was conducted for each spatial scale of the impact function.

\subsection{Uncertainty analysis of the LUC-induced surface temperature change}

After validating the impact functions, an uncertainty analysis was performed to estimate the potential LUC-induced surface temperature spread across Shikoku that resulted from the different LUC scenarios. While there are many sources of uncertainty, we focused the uncertainty of surface warming associated with different scenarios of LUC by means of the intensity and geographical distribution of LULC relative to the reference LULC. For the uncertainty analysis, the Monte Carlo method was used to generate a number of artificial LUC scenarios. Of the many scenarios generated, this study focused on 6 LUC conversion types, including (1) forest to paddy, (2) forest to building lots, (3) paddy to forest, (4) paddy to building lots, (5) building lots to paddy, and (6) building lots to forest. These conversion types were chosen because the dominant LULCs (74.6\% in 2006) in the study area involve forested land. In addition, urbanization is known to cause significant warming. Furthermore, in recent decades, the dominant LUC in the study area involved the conversion of paddies to building lots (Yoshida et al. 2012).

The uncertainty analysis was performed as follows. (1) To account for various LUC types and geographical distributions, a random number of samples were obtained from a uniform distribution between 0 and 1 for a given $5 \mathrm{~km}$ grid cell. (2) If the sampled value was $<0.5$, no LUC was set for the grid cell. Instead, another random number was generated from a uniform distribution that varied between 1 and 6 (this number corresponds to the LUC types mentioned above, e.g. '1' means the conversion of forest to paddy). (3) The sampled LUC was applied to any of the $100 \mathrm{~m}$ mesh NLNI data from 2006 that were located within the selected $5 \mathrm{~km}$ grid cell of the impact function. (4) A set of land-surface parameter values for the grid cell and the sampled LUC were computed (Fig. 3b). (5) For a given grid cell, the responses of $T_{\text {aver }} T_{\text {max }}$ and $T_{\min }$ to changes in each land-surface parameter value were derived from the corresponding cubic spline functions. The applied resolution of the impact function was decided by its performance in the validation. The resolution that most accurately simulated Shikoku-mean surface temperature was used across Shikoku. Next, the temperature responses to the 5 land-surface parameters were summed linearly. (6) Steps (1) through (5) were repeated for all grid cells that were located within the Shikoku area. In addition, the simulated changes in temperatures across the grid cells were averaged where each of the 6 LUC scenarios (1-6) occurred (however, these values were not the average temperature changes across the Shikoku area). (7) These procedures were repeated 10000 times to account for multiple LUC scenarios. This procedure resulted in various LUC scenarios with different geographical patterns and intensities. We averaged the simulated temperature change for each LUC scenario (but not over the Shikoku area) to isolate the LUC-induced temperature changes in residential (urban and rural) areas relative to nonresidential areas (e.g. forest). Based on these LUCs, the temperature responses were calculated and averaged across Shikoku for each of the 6 LUC scenarios. We used the high-resolution NLNI data rather than the coarse resolution GLCC data to take into account the actual spatial LULC distribution at a smaller scale. 


\section{RESULTS}

\subsection{Derived impact functions}

The typical responses of $T_{\text {aver }}, T_{\max }$ and $T_{\min }$ to the land-surface parameter changes are shown in Fig. 4. These responses were obtained from the sensitivity analysis for the entire Shikoku area. The major characteristics of the $T_{\text {ave, }}, T_{\max }$ and $T_{\min }$ responses for land-surface parameter changes were similar to each other. However, the sensitivities differed among the 3 temperatures. For example, the slope of the $T_{\max }$ spline function in the high albedo area $(0.6<\alpha)$ was steeper than the slope of $T_{\text {ave }}$ and $T_{\min }$ (Fig. 4a). This result suggested that $T_{\max }$ was more sensitive to surface albedo than the other variables. In addition, the response of $T_{\max }$ was more sensitive to the evaporative efficiency ( $\beta$ ), especially in the lower evaporative efficiency area $(\beta<0.4$; Fig. $4 \mathrm{~b})$. In contrast, the responses of $T_{\max }$ to changes in the remaining parameters (roughness length, heat capacity, and thermal conductivity) were weak relative to the responses to the surface albedo and evaporative efficiency parameters. However, $T_{\text {ave }}$ and $T_{\min }$ were more sensitive to heat capacity and thermal conductivity (relative to $T_{\max }$ ) (Fig. 4d,e). Furthermore, a comparatively lower sensitivity to roughness length change was observed for all variables (Fig. 4c).

\subsection{Performance of the impact-function method}

Fig. 5 depicts the LUC-induced warming over Shikoku between 1987 and 2006 that was simulated with the RCM and impact-function methods. The same historical LUC data were applied for 2 methods. For the RCM method, the simulated temperature differences between the 2 simulations (the historical LULC run minus the fixed-LULC run; Fig. 3a) represent the historical LUC impacts on warming. The warming values that were simulated with the $\mathrm{RCM}$ method were $+0.041,+0.050$, and $+0.039^{\circ} \mathrm{C}$ $20 \mathrm{yr}^{-1}$ for $T_{\text {aver }} T_{\max }$ and $T_{\min }$, respectively. The warming mainly resulted from the deforestation that occurred before 2000, the reforestation that occurred after 2000, and the conversion of paddies to building lots and roads throughout the study period (Yoshida et al. 2012).

The historical LUC-induced warming that was obtained from the impact-function method corresponded to the RCM method. However, the rootmean-square error (RMSE) between the 2 methods varied with the grid size of the impact functions
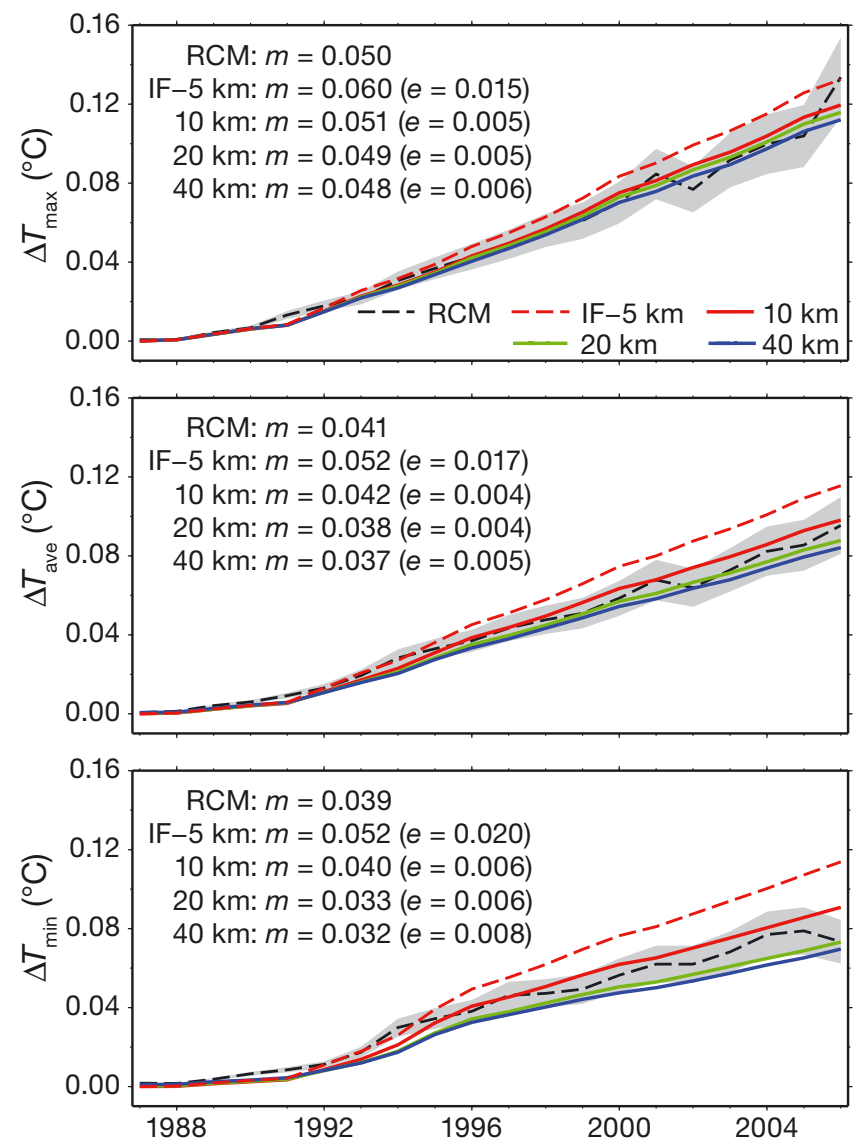

Fig. 5. Historical land-use change (LUC)-induced surface warming in Shikoku for the 3 temperature variables $\left(\Delta T_{\text {ave, }}\right.$ $\Delta T_{\max }$ and $\Delta T_{\min }$ ) between 1987 and 2006 relative to the starting values in 1987. Black dotted line: regional climate model (RCM) method results; grey shading: $\pm 20 \%$ error range (for reference). Lines represent different grid sizes. Mean surface warming during 1987-2006 (m) was calculated for each simulation and root-mean-square-errors $(e)$ with respect to the RCM method were calculated for each grid size of the impact-function method

(Fig. 5). The impact functions for $T_{\text {ave }}$ at a grid size of $10 \mathrm{~km}$ and $20 \mathrm{~km}$ had lower RMSE $\left(0.004^{\circ} \mathrm{C} 20 \mathrm{yr}^{-1}\right)$ values than the impact functions at other grid sizes ( 0.017 and $0.005^{\circ} \mathrm{C} 20 \mathrm{yr}^{-1}$ for $5 \mathrm{~km}$ and $40 \mathrm{~km}$ ). Similarly, for $T_{\max }$ and $T_{\min }$ a lower RMSE was found for the $10 \mathrm{~km}$ and $20 \mathrm{~km}$ impact functions relative to other impact functions. For all variables, the $10 \mathrm{~km}$ and $20 \mathrm{~km}$ impact functions matched the RCM method results with an RMSE of $10-15 \%$ relative to the RCM method results throughout the analyzed period. Although the $10 \mathrm{~km}$ and $20 \mathrm{~km}$ impact functions showed the same value in RMSE, the absolute value of mean error (impact-function minus RCM) was smaller for the $10 \mathrm{~km}$ impact functions $\left(0.001^{\circ} \mathrm{C}\right.$ $\left.20 \mathrm{yr}^{-1}\right)$ than the $20 \mathrm{~km}$ impact functions $\left(-0.003^{\circ} \mathrm{C}\right.$ $20 \mathrm{yr}^{-1}$ ). 


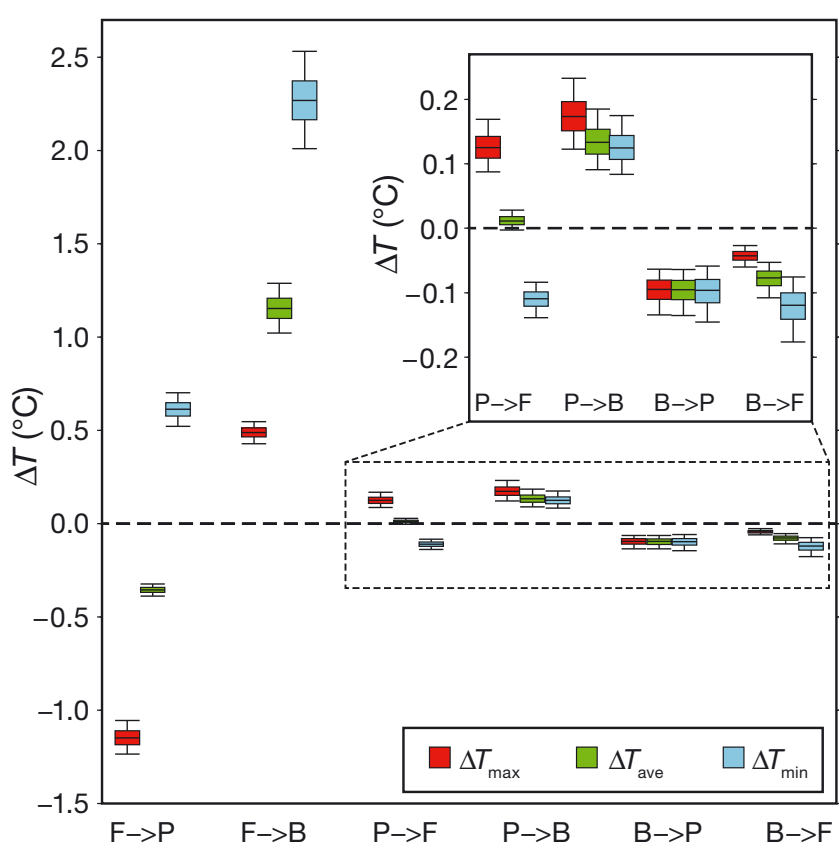

Fig. 6. Box plots of simulated warming relative to the 1987 averages in Shikoku for the 3 temperature variables $\left(\Delta T_{\text {ave }}\right.$ $\Delta T_{\max }$, and $\left.\Delta T_{\min }\right)$ and the 10000 possible land-use change (LUC) scenarios. Six LUC-type conversions are considered, including forest to paddy $(\mathrm{F} \rightarrow \mathrm{P})$, forest to building lots $(\mathrm{F} \rightarrow \mathrm{B})$, paddy to forest $(\mathrm{P} \rightarrow \mathrm{F})$, paddy to building lots $(\mathrm{P} \rightarrow \mathrm{B})$, building lots to paddy $(\mathrm{B} \rightarrow \mathrm{P})$, and building lots to forest $(\mathrm{B} \rightarrow \mathrm{F})$. The ranges of the box plots represent the different LUC extents (e.g. lower LUC corresponds to lower temperature change). Lower and upper horizontal lines: 5th and 95th percentiles, respectively; lower and upper box hinges: 25th and 75th percentiles, respectively

\subsection{Spread of the LUC-induced warming}

Fig. 6 shows the spread of the LUC-induced temperature changes that were associated with different LUC scenarios. Here, we used the $10 \mathrm{~km}$ grid impact functions because they were the most accurate across different scales. The extent of the observed temperature change varied substantially between the different LUC scenarios depending on the variables. The spreads of the $T_{\text {aver }} T_{\max }$ and $T_{\min }$ values were -0.4 to $1.2^{\circ} \mathrm{C},-1.1$ to $0.5^{\circ} \mathrm{C}$, and -0.1 to $2.3^{\circ} \mathrm{C}$, respectively (based on the median value of each box plot). The conversion of forest lands to building lots $(\mathrm{F} \rightarrow \mathrm{B})$ increased the temperatures of all variables. In contrast, the conversion of forest lands to paddy fields $(\mathrm{F} \rightarrow \mathrm{P})$ resulted in a lower $T_{\max }$ and $T_{\text {aver }}$ and produced the second largest increase in $T_{\min }$. The LUC for the conversion from paddy fields to building lots $(\mathrm{P} \rightarrow \mathrm{B})$ had a small impact relative to the impacts of the 'deforestation' scenarios $(\mathrm{F} \rightarrow \mathrm{B}$ and $\mathrm{F} \rightarrow \mathrm{P})$. In addition, the induced temperature increase reached up to $0.23^{\circ} \mathrm{C}$ for $T_{\max }, 0.19^{\circ} \mathrm{C}$ for $T_{\text {aver }}$ and $0.18^{\circ} \mathrm{C}$ for $T_{\min }$. For the remaining LUCs $(\mathrm{P} \rightarrow \mathrm{F}, \mathrm{B} \rightarrow \mathrm{P}$, and $\mathrm{B} \rightarrow \mathrm{F})$, the LUC-induced temperature changes were always less than the LUC-induced temperature changes of the $\mathrm{F} \rightarrow \mathrm{B}, \mathrm{F} \rightarrow \mathrm{P}$, and $\mathrm{P} \rightarrow \mathrm{B}$ scenarios.

\section{DISCUSSION}

\subsection{The effects of grid size on impact-function performance}

The performance of the impact-function is affected by grid size (Fig. 5). Thus, the effects of grid size on the impact functions that are used for simulations must be studied in detail. Therefore, we determined the RMSE values between the RCM and impactfunction methods at various grid sizes (ranging from 5-40 km). These RMSEs are summarized in Fig. 7.

The calculated RMSE values decreased substantially for all variables after box-averaging (from 5 to 10 km; Fig. 7). Thereafter, the RMSE values gradually increased with increasing grid size with a minimum at grid sizes of 10 and $20 \mathrm{~km}$. The improved performance (represented by a smaller RMSE) of the 10 and $20 \mathrm{~km}$ grids relative to the $5 \mathrm{~km}$ grid potentially occurred because the impact-function method did not account for horizontal advection or crossparameter effects. Another possible reason is noise caused from internal variability, which distorted the spline fitting in the composition of impact functions. Box-averaging may cancel these effects and result in a good match between the 2 methods.

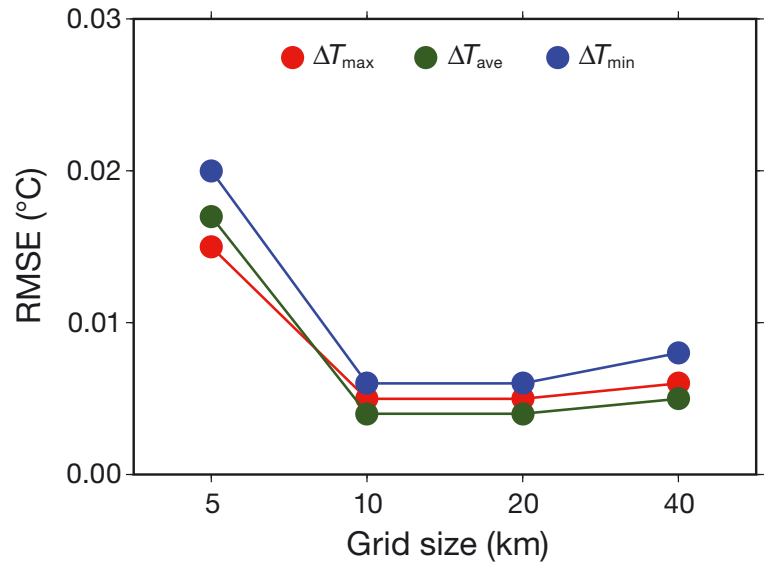

Fig. 7. The root-mean-square-errors (RMSEs) of the simulated land-use change (LUC)-induced historical warming for the $\Delta T_{\text {aver }} \Delta T_{\max }$ and $\Delta T_{\min }$ temperature variables for 19872006 in Shikoku. RMSE values represent the error of the impact-function method at various grid sizes relative to the results from the RCM method 
The gradual decrease in performance from the grid sizes of 10 and $20 \mathrm{~km}$ to the grid size of $40 \mathrm{~km}$ potentially occurred because the temperature responses to changes in the land-surface parameter values from the impact functions are oversimplified by the box-averaging. The RMSE values for $T_{\min }$ are always greater than those for $T_{\text {ave }}$ and $T_{\max }$. As shown in Fig. $4, T_{\min }$ is sensitive to changes in heat capacity $(\mathrm{c} \rho)$ and thermal conductivity $(\lambda)$ when these values are low (c $\rho<1 \times$ $10^{6}$ and $\left.\lambda<0.6\right)$. These are similar to the values that are given for forest terrain $\left(\mathrm{c} \rho=1 \times 10^{6} ; \lambda=0.7\right.$; Table 2). The creation of the impact-function required caution for these sensitive value ranges; however, we did not account for any cross-term effect and thus $T_{\min }$ estimation was poor compared to that of $T_{\text {ave }}$ and $T_{\max }$. Also, because the most mountainous areas in the study area (which are characterized by complex terrains) are covered by forest, box-averaging may decrease the impact of topography in mountainous areas, which results in smoother temperature responses (particularly for $T_{\min }$ ). In contrast, $T_{\text {ave }}$ and $T_{\max }$ respond to surface albedo and evaporative efficiency more than they respond to other parameters (Fig. $4 \mathrm{a}, \mathrm{b}$ ). However, the responses of $T_{\text {ave }}$ and $T_{\max }$ to lower surface albedo values $(\alpha<0.2)$ and evaporative efficiencies $(\beta<0.3)$, which are near the forest land values $(\alpha=0.1 ; \beta=0.3)$, were not very sensitive (Fig. $4 a, b)$. These insensitive responses contributed to the lower RMSE values for $T_{\text {ave }}$ and $T_{\max }$ relative to $T_{\min }$.

\subsection{Uncertainty of surface temperature change associated with LUC scenarios}

As shown in Fig. 6, the greatest warming due to LUC occured when forest land is converted to building lots $\left(+1.0\right.$ to $+1.3^{\circ} \mathrm{C}$ for $\left.T_{\text {ave }}\right)$. This area currently corresponds to non-residential areas. The greatest warming occurred in the 'deforestation/urbanization' scenarios $(\mathrm{F} \rightarrow \mathrm{B})$ because forest land is the most dominant LULC in the study area. In addition, urban heat islands are known to cause significant warming (Kimura \& Takahashi 1991). The other LUC from forest land, the $\mathrm{F} \rightarrow \mathrm{P}$ scenario, showed different responses among temperatures: warming for $T_{\max }$ and $T_{\text {aver }}$ and cooling for $T_{\min }$. This is because an increase of evaporative efficiency (forest land to paddy field: $0.3-0.8)$ contributes surface cooling for $T_{\max }$ and $T_{\text {ave }}$ and increases of heat capacity $\left(1.0 \times 10^{6}\right.$ to $2.3 \times 10^{6} \mathrm{~J}$ $\mathrm{m}^{-3} \mathrm{~K}^{-1}$ ) and thermal conductivity $\left(0.7\right.$ to $1.6 \mathrm{~W} \mathrm{~m}^{-1}$ $\mathrm{K}^{-1}$ ) cause surface warming for $T_{\min }$ (Fig. 4). Relative to these temperature changes, the temperature changes associated with the LUCs, such as $\mathrm{B} \rightarrow \mathrm{P}$ and
$\mathrm{B} \rightarrow \mathrm{F}$ (approximately $-0.1^{\circ} \mathrm{C}$ for $T_{\text {ave, }} T_{\max }$ and $T_{\min }$ ), were small. This result occurred because of the limited original extent of building lots. The area of the building lots only accounted for $3.6 \%$ of the Shikoku area. In contrast, the area of the forest land accounted for $74.6 \%$ of the Shikoku area (Yoshida et al. 2012). Nevertheless, Fig. 6 clearly demonstrates the magnitude of the potential impacts of LUCs on local warming and the uncertainties that result from the different LUC scenarios. If we compare LUC-induced warming to the warming that results from other causes (using climatic change as the example), the maximum impacts of the LUCs on warming $(+1.0$ to $+1.3^{\circ} \mathrm{C}$ for $T_{\text {ave }}$ ) roughly correspond to the global annual-mean surface warming in the 2040 decade (with some variations across GCMs; the differences across the emission scenarios are not during this period; IPCC 2007). Although the temporal and spatial scales differ, this comparison could help us to understand the magnitude of LUC-induced warming. Bagley et al. (2012) performed similar comparisons for changes in global crop yield due to future climate change and different LUC scenarios. However, the largest decrease in $T_{\text {ave }}$ was observed when forest lands were converted to paddy fields $(-0.40$ to $-0.35^{\circ} \mathrm{C}$ ). This result occurred due to the drastic change in $\beta$, which changed from 0.3 for forest land to 0.8 for paddy fields. Because paddy fields in summer have water surface for cultivation, the value of parameter $\beta$ for paddy fields is higher than that for forest land. In addition, evaporative cooling contributes to the decreasing $T_{\text {ave }}$. Based on the area average, the magnitude of this cooling offsets the projected warming in the 2010 decade, which suggests that it is impossible to offset climate-changeinduced warming in the Shikoku with land-use management efforts such as the reforestation or reactivation of paddies in urban areas.

\subsection{Characteristics of the impact-function method, and comparison to the RCM method}

The impact-function method is useful when computer resources are limited. This method can be used to perform uncertainty analysis without a computationally heavy model. Although computer resources for environmental studies have become more available, these resources are not always adequate for simulating very comprehensive models that use fine grid sizes (Challinor et al. 2009). Therefore, the impact-function method is a potentially helpful alternative for performing uncertainty analysis. 
The impact functions that were developed in this study partially rely on the physical principles that were modeled in the RCM (with some errors that are presented in the Results section) when the given LUC was within the range of the RCM sensitivity analysis. Because the impact functions are statistical models, users must exercise caution when extrapolating them. Furthermore, composed impact functions should always be validated as far as possible. These requirements are disadvantages of the impactfunction method. In addition, the reliabilities of the impact functions depend on the sample size used to create them. Increasing the sample size may enable the use of statistical models that account for crossparameter or nonlinear effects. However, a trade-off exists between the complexity and reliability of the statistical models, and the sample size that can be processed with limited computer resources.

\section{CONCLUSIONS}

This study developed impact functions that approximated the effects of the RCM-simulated LUCs on summer temperatures in Shikoku without requiring computationally heavy simulations. The developed impact functions were evaluated by comparing them to the RCM results that were obtained with the RCM method. The impact functions were then used during uncertainty analysis to estimate the potential changing surface temperature ranges in the areas that were associated with the various LUC scenarios.

The reliability of the impact functions varied with grid size. The best agreement was obtained between the impact functions with a $10 \mathrm{~km}$ grid size and the RCM method results (when a $5 \mathrm{~km}$ grid was used for the RCM method), which yielded an RMSE of 10$15 \%$. Therefore, the impact-function method is a potential alternative for RCM simulations when computational resources are limited. We believe that the impact-function method is flexibly applicable to various LULC types. However, further study is needed to conclude overall applicability of the impact-function method to LULC types other than those considered in this study.

Our results suggest that the possible warming induced by the LUCs is similar to the warming projected by climate change in the decade of 2040 in Shikoku (with some variations across different GCMs and emission scenarios). Although land-use management may reduce warming, cooling effects are limited in their ability to offset warming trends that result from climate change. This study emphasizes the need for developing adaptation measures other than land-use management, and for avoiding further deforestation and paddy abandonment at a regional scale to minimize LUC-induced warming.

Acknowledgements. This study was financially supported by the Research Program on Climate Change Adaptation (RECCA) of the Ministry of Education, Culture, Sports, Science, and Technology of Japan and by the 'Development of technologies for mitigation and adaptation to climate change in Agriculture, Forestry, and Fisheries' program of the Ministry of Agriculture, Forestry and Fisheries of Japan. Computations were conducted with the computer cluster system of the Computer Center for Agriculture, Forestry, and Fisheries Research. Our thanks are extended to the editor and 3 anonymous reviewers for their many informative and invaluable comments.

\section{LITERATURE CITED}

Bagley JE, Desai AR, Dirmeyer PA, Foley JA (2012) Effects of land cover change on moisture availability and potential crop yield in the world's breadbaskets. Environ Res Lett 7:014009

Challinor AJ, Osborne T, Morse A, Shaffrey L, Wheeler T, Weller H, Vidale PL (2009) Methods and resources for climate impacts research. Bull Am Meteorol Soc 90: 836-848

- Fu C (2003) Potential impacts of human-induced land cover change on East Asia monsoon. Global Planet Change 37: 219-229

> Good P, Ingram W, Lambert FH, Lowe JA and others (2012) A step-response approach for predicting and understanding non-liner precipitation changes. Clim Dyn 39:2789-2803

$>$ Hahmann AN, Dickinson RE (1997) RCCM2-BATS model over tropical south America: applications to tropical deforestation. J Clim 10:1944-1964

Hanasaki N, Masutomi Y, Takayashi K, Hijioka Y, Harasawa H, Matsuoka Y (2007) Development of a global water resources scheme for climate change policy support models. Environ Syst Res 35:367-374 (in Japanese with English abstract)

Iizumi T, Yokozawa M, Nishimori M (2009) Development of impact functions on regional paddy rice yield in Japan for integrated impact assessment models. J Agric Meteorol 65:179-190

IPCC (2007) Climate change 2007: the physical science basis. Contribution of Working Group I to the Fourth Assessment Report of the Intergovernmental Panel on Climate Change. Cambridge University Press, Cambridge

> Kain JS (2004) The Kain-Fritsch convective parameterization: an update. J Appl Meteorol 43:170-181

Kalnay E, Cai M (2003) Impact of urbanization and land-use change on climate. Nature 423:528-531

Kimura F, Takahashi S (1991) The effects of land-use and anthropogenic heating on the surface temperature in the Tokyo metropolitan area: a numerical experiment. Atmos Environ 25:155-164

Kondo J (1994) Meteorology of water environment. Asakura Publishing, Tokyo

Loveland TR, Reed BC, Brown JF, Ohlen O, Zhu Z, Mer- 
chant YJW (2000) Development of a global land cover characteristics database and IGBP DISCover from $1 \mathrm{~km}$ AVHRR data. Int J Remote Sens 21:1303-1330

MAFF (2007) Crop statistics. Available at www.e-stat.go.jp/ SG1/estat/List.do?lid=000001061493 (in Japanese)

Mariotti L, Coppola E, Sylla MB, Giorgi F, Piani C (2011) Regional climate model simulation of projected 21st century climate change over an all-Africa domain: comparison analysis of nested and driving model results. J Geophys Res 116:D15111, doi:10.1029/2010JD015068

MLITT (2012) National Land Numerical Information. Ministry of Land, Infrastructure, Transport and Tourism, Tokyo

Murphy JM, Booth BBB, Collins M, Harris GR, Sexton DMH, Webb MJ (2007) A methodology for probabilistic predictions of regional climate change form perturbed physics ensembles. Philos Trans R Soc Lond A 365:1993-2028

Nakanishi M, Niino H (2004) An improved Mellor-Yamada level-3 model with condensation physics: its design and verification. Boundary-Layer Meteorol 112:1-31

Onogi K, Tsutsui J, Koide H, Sakamoto M and others (2007) The JRA-25 Reanalysis. J Meteorol Soc Jpn 85:369-432

Ramankutty P, Ryan M, Lawes R, Speijers J, Renton M (2013) Statistical emulators of a plant growth simulation model. Clim Res 55:253-265

Reynolds RW, Rayner NA, Smith TM, Stokes DC, Wang W (2002) An improved in situ and satellite SST analysis for

Editorial responsibility: Mikhail Semenov,

Harpenden, UK climate. J Clim 15:1609-1625

Ruane AC, McDermid S, Rosenzweig C, Baigorria GA, Jones JW, Romero CC, Cecil LD (2013) Carbon-temperature-water change analysis for peanut production under climate change: a prototype for the AgMIP coordinated climate-crop modeling project (C3MIP). Glob Change Biol 20:394-407

Saito K, Ishida J, Aranami K, Hara T, Segawa T, Narita M, Honda Y (2007) Nonhydrostatic atmospheric models and operational development at JMA. J Meteorol Soc Jpn 85B:271-304

Schlenker W, Lobell DB (2010) Robust negative impacts of climate change on African agriculture. Environ Res Lett 5:1-8, doi:10.1088/1748-9326/5/1/014010

> Sen OL, Wang Y, Wang B (2004) Impact of Indochina deforestation on the East Asian summer monsoon. J Clim 17: $1366-1380$

Sheehy JE, Mitchell PL, Ferrer AB (2006) Decline in rice grain yields with temperature: models and correlations can give different estimates. Field Crops Res 98:151-156

Yoshida R, Iizumi T, Nishimori M, Yokozawa M (2012) Impacts of land-use changes on surface warming rates and rice yield in Shikoku, western Japan. Geophys Res Lett 39:L22401, doi:10.1029/2012GL053711

> Yoshida R, Sawada M, Yamazaki T, Ohta T, Hiyama T (2013) Influence of land cover change on regional water cycles in eastern Siberia. J Appl Meteorol Climatol 52:484-497

Submitted: July 15, 2013; Accepted: November 13, 2013 Proofs received from author(s): January 29, 2014 